\title{
DIGESTIBILIDADE E RETENĈ̃O DE NITROGÊNIO DE ALIMENTOS PARA PAPAGAIOS VERDADEIROS (Amazona aestiva)
}

\author{
Digestibility and protein retention of foods for blue-fronted parrot (Amazona aestiva)
}

\author{
Carlos Eduardo do Prado Saad ${ }^{1}$, Walter Motta Ferreira² ${ }^{2}$ Flávia Maria de Oliveira Borges ${ }^{3}$, Leonardo Boscoli Lara ${ }^{4}$
}

RESUMO

Foram utilizados 34 papagaios verdadeiros alojados em gaiolas metabólicas e distribuídos em blocos ao acaso em 17 tratamentos (T1 - ração referência, T2 - semente de girassol, T3 - aveia, T4 - gema de ovo, T5 - ovo integral, T6 - clara de ovo, T7 - germe de trigo, T8 - farelo de trigo, T9 - milho moído, T10 - milho gelatinizado, T11- farelo de girassol, T12 - levedura, T13 - polpa cítrica, T14 - mamão, T15 - banana, T16 - farelo de soja, T17 - soja micronizada), durante três períodos de colheita, totalizando seis repetições (102 unidades experimentais). Para avaliação dos alimentos utilizou-se a técnica de substituição. Foram avaliados os coeficientes de digestibilidade da matéria seca (MS) e matéria orgânica (MO) e a retenção de nitrogênio dos alimentos, comparando os tratamentos dois a 17, sendo que o delineamento experimental foi em blocos ao acaso, com 16 tratamentos, três períodos experimentais e seis repetições. O tratamento um (ração referência) foi utilizado apenas para os cálculos de substituição, não fazendo parte das análises estatísticas. As médias foram comparadas pelo teste Scott-Knott. Os resultados obtidos permitiram concluir que: 1 - Os papagaios apresentaram alta digestibilidade da MS e MO para os alimentos: milho gelatinizado, gema de ovo, semente de girassol, aveia, ovo integral, milho moído, mamão e banana, podendo ser considerados como boas opções de escolha para a composição de uma dieta completa; 2 - alimentos como a polpa cítrica e o farelo de girassol apresentaram baixas digestibilidades aparente e verdadeira da MS e MO, e devem ser utilizados em níveis baixos e com moderação na formulação de rações para estas aves; 3 - a retenção de nitrogênio verdadeiro foi positiva para todas as aves, sugerindo que ainda estejam em anabolismo, entretanto, devido ao alto coeficiente de variação, esta medida parece não ser adequada para expressar o coeficiente real de retenção de nitrogênio para papagaios.

Termos para indexação: Animais silvestres, aves, nutrição.

\section{ABSTRACT}

Were used 34 blue fronted parrot, distributed in blocks with 17 treatments (T1 - reference diet, T2 - sunflower seed, T3 - oat, T4 - egg yolk, T5 - integral egg, T6 - egg white, T7 - wheat germen, T8 - wheat bran, T9 - triturated corn, T10 - jellied corn, T11 - sunflower bran, T12 - yeast, T13 - citric pulp, T14 - papaya, T15 - banana, T16 - soy bran, T17 - extruded soy) during three periods, totaling six repetitions (102 experimental units). For foods evaluation the substitution methodology was used. They were appraised the digestibility coefficients of the dry matter (DM) and organic matter (OM) and the protein retention of the evaluated foods. Were compared the treatments two to 17. The treatment 1 (reference diet) it was just used for the substitution calculations, not being part of the statistical analyses. The averages were compared by the test Scott-Knott. The obtained results allowed to conclude that: 1 - foods as the jellied corn, the egg yolk and the sunflower seed, as well as the oat, integral egg, triturated corn, papaya and banana, they possess high DM and OM digestibility for parrots, could be considered as good choice options for the composition of a complete diet; 2 - foods as the citric pulp and the sunflower bran presented low apparent and true digestibility of the DM and OM and they should be used in low levels and with moderation in the formulation of rations for these birds; 3 - the true nitrogen retention was positive for all the birds, what suggests that the same ones can be depositing still tissues, however, due to the high variation coefficient, this measured it seems not to be adapted to express the real nitrogen retention coefficient for parrots.

Index terms: Wild animals, birds, nutrition.

\section{(Recebido em 4 de novembro de 2005 e aprovado em 30 de maio de 2006}

\section{INTRODUÇÃO}

Vários fatores contribuem para erros no manejo alimentar das aves silvestres criadas em cativeiro; a simples extrapolação dos hábitos alimentares na natureza para o cativeiro pode provocar superestimativa do fornecimento de energia. Como exemplo, na natureza os psitacídeos são encontrados consumindo grande variedade de alimentos, incluindo frutas, bagas, flores, brotos de plantas, legumes, insetos, larvas e sementes (ULLREY et al., 1991). Alguns chegam a consumir partes de mais de 80 espécies de vegetais. Eles estão acostumados com dieta altamente nutritiva, contendo teores elevados de ácidos graxos,

\footnotetext{
'Zootecnista, D.Sc. em Nutrição de Animais Silvestres - AnimalNutri - Rua Dr. Armando Amaral, 122 - Padre Dehon - $37200-000$ - Lavras, MG eduardosaad@animalnutri.com.br; saadzoo@ufla.br.

${ }^{2}$ Zootecnista, D. Sc., Professor Adjunto, Escola de Veterinária - Universidade Federal de Minas Gerais/UFMG - Av. Antônio Carlos, 6627 - Pampulha 30.123-970 - Belo Horizonte, MG - waltermf@vet.ufmg.br

${ }^{3}$ Médica Veterinária, D.Sc., Professora Adjunta - Departamento de Zootecnia/DZO - Universidade Federal de Lavras/UFLA - Cx. P. 3037 - 37200-000 Lavras, MG

${ }^{4}$ Médico Veterinário, D.Sc., Rua Jurutau, 1800 - Parque Industrial II - 86.703-070 - Arapongas, PR - leoboscoli@gmail.com
} 
moderados de proteína e relativamente baixos de carboidratos. Mediante essas observações, concluiu-se erroneamente que essas aves necessitam de dietas mais energéticas em cativeiro, sem levar em conta as diferenças no grau de atividade e oferta de alimentos nos dois ambientes.

A alimentação de psitacídeos em cativeiro tem sido feita até o momento, em sua maior parte, de maneira empírica, baseando-se na observação de suas preferências e hábitos alimentares na natureza, além da extrapolação de dados de aves domésticas. Na alimentação de aves domésticas que preocupam com o custo-benefício, o uso de dietas completas, ou rações, é prática corrente. As dietas completas permitem fornecer aos animais os nutrientes de forma balanceada e em quantidades exatas, impedindo a seleção de itens mais palatáveis, o que comumente ocorre na alimentação de psitacídeos, quando se oferece uma dieta composta de vários tipos de alimentos.

A formulação de rações para aves silvestres, deve levar em consideração dois pontos importantes: o conhecimento de suas necessidades nutricionais e dos nutrientes disponíveis em cada ingrediente ou matéria-prima utilizada na elaboração da dieta. Na nutrição animal, todos os nutrientes são importantes, mas a avaliação dos alimentos tem sido orientada à energia, que representa o alimento como um todo, e ao conteúdo de proteína, porque os dois são os componentes mais importantes das dietas em termos quantitativos (MEJÍA \& FERREIRA, 1996). O conhecimento da digestibilidade da matéria seca de um alimento para determinada espécie direciona a escolha de ingredientes mais adequados para a formulação de dietas. $\mathrm{O}$ mesmo pode ser dito com relação à proteína.

Segundo Carciofi (1996), o uso de experimentos in vivo visando a avaliação da biodisponibilidade de nutrientes de alimentos para psitacídeos em cativeiro, encontra-se reduzido. Earle \& Clarke (1991), trabalhando com Periquito-australiano (Melopsittacus undulatus), avaliaram a porcentagem de metabolização aparente da proteína bruta, extrato etéreo, extrativo não nitrogenado e da energia do painço branco, painço vermelho, alpiste e da mistura dos três. Os autores concluíram que a porcentagem de metabolização dos nutrientes é alta, sendo na média maior que $80 \%$. Ainda, segundo Carciofi (1996), não foi localizado nenhum estudo desta natureza utilizando papagaios brasileiros. Isto denota a grande carência de informações e a necessidade de estudos sobre os alimentos utilizados em cativeiro. Tais estudos são imprescindíveis ao desenvolvimento dos conhecimentos sobre nutrição em cativeiro de psitacídeos, servindo de suporte para futuros estudos sobre necessidades nutricionais.
Objetivou-se com este trabalho determinar e comparar a digestibilidade da matéria seca, matéria orgânica e a retenção de nitrogênio dos alimentos utilizados para psitacídeos.

\section{MATERIAL E MÉTODOS}

Foram utilizados 34 papagaios-verdadeiros (Amazona aestiva) sexados, distribuídos em blocos ao acaso, em três períodos experimentais, sendo que cada período experimental constituiu um bloco, e 17 tratamentos com seis repetições por tratamento, totalizando 102 unidades experimentais.

Para avaliação dos alimentos utilizou-se o método de substituição descrita por Matterson et al. (1965).

Os tratamentos tiveram como uma ração extrusada para psitacídeos (ração referência - T1) com substituição de $29,76 \%$ (base da matéria natural) pelos alimentos testes, mais a incorporação de $0,24 \%$ de premix, para que todas as rações apresentassem o mesmo teor de minerais e vitaminas. Os tratamentos foram: T1 - ração referência, T2 - semente de girassol, T3 - aveia, T4 - gema de ovo, T5 - ovo integral, T6 - clara de ovo, T7 - germe de trigo, T8 farelo de trigo, T9 - milho moído, T10 - milho gelatinizado, T11- farelo de girassol, T12 - levedura de cerveja, T13 polpa cítrica, T14 - mamão desidratado, T15 - banana desidratada, T16 - farelo de soja, T17 - soja micronizada. Posteriormente todas as rações foram extrusadas, igualando a forma de apresentação dos tratamentos, com exceção à semente de girassol (T2) que foi oferecida "in natura”. Para a avaliação da semente de girassol, foi considerada a relação $65,83 \%$ de semente e $34,17 \%$ de cascas, sendo essa porcentagem obtida descascandose, manualmente, $500 \mathrm{~g}$ de sementes. Para o cálculo do consumo, todas as cascas encontradas na bandeja coletora foram desprezadas, considerando-se como desperdício apenas as sementes inteiras. Os cálculos de consumo foram ajustados somente para semente descorticada.

As rações teste foram fornecidas à vontade durante 12 dias (sete dias de adaptação e cinco de colheita de dados) em cada um dos três períodos. Foram registradas as quantidades de ração-teste ingeridas por unidade experimental, tomando-se o cuidado de separar e pesar as sobras retidas nas bandejas de excreta.

Para a avaliação dos coeficientes de digestibilidade da MS e MO e dos coeficientes de retenção aparente e verdadeiro do nitrogênio procedeu-se à colheita total de excreta nos últimos cinco dias das três fases experimentais. Ao final do terceiro período 
experimental todas as aves foram colocadas em jejum, durante 72 horas, para a obtenção do fator de correção para os coeficientes de digestibilidade e retenção verdadeiros. As aves em jejum receberam uma solução de água e glicose (cinco gramas de glicose/ave/dia), visando o fornecimento de quantidades mínimas de energia para as aves sem, contudo, interferir na obtenção dos valores de perdas endógenas de nutrientes, conforme o recomendado por McNab \& Blair (1988).

Os parâmetros avaliados foram os coeficientes de digestibilidade da MS e MO e a retenção de nitrogênio dos alimentos. Estes coeficientes foram calculados segundo Matterson et al. (1965). A composição das amostras dos alimentos puros (Tabela 1), das rações teste (Tabela 2) e das excretas foram realizadas no Laboratório de Nutrição Animal da Escola de Veterinária da UFMG e no Laboratório de Nutrição do Instituto Mineiro de Agropecuária, segundo a metodologia da AOAC (CUNNIFF, 1995).

O procedimento estatístico adotado foi o GLM do pacote estatístico SAS Institute (1995). Foram comparados os tratamentos dois a 17 , sendo que o delineamento experimental foi em blocos ao acaso, com 16 tratamentos, três períodos experimentais e seis repetições. O tratamento um (ração referência) foi utilizado apenas para os cálculos de substituição, não fazendo parte das análises estatísticas. As médias dos parâmetros avaliados foram comparadas pelo teste Scott-Knott.

\section{RESULTADOS E DISCUSSÃO}

$\mathrm{Na}$ Tabela 3, encontram-se os valores de digestibilidade aparente e verdadeira (\%) da matéria seca (MS) e da matéria orgânica (MO) dos alimentos avaliados. O milho gelatinizado, a gema de ovo e a semente de girassol apresentaram $(\mathrm{P}<0,05)$ os maiores coeficientes de digestibilidades aparente da MS (DAMS) e da MO (DAMO) e coeficiente de digestibilidade verdadeiro da MO (DVMO) com valores iguais $(\mathrm{P}>0,05)$ entre si. Com relação ao coeficiente de digestibilidade verdadeiro da MS (DVMS), a semente de girassol apresentou um menor coeficiente $(\mathrm{P}<0,05)$ quando comparada aos outros dois alimentos já citados.

A digestibilidade aparente e verdadeira, tanto da MS quanto da MO, da aveia, ovo integral, milho moído, mamão e banana foram significativamente semelhantes e acima de $75 \%$, o que pode ser considerada relativamente alta.

TABELA 1 - Composição química $(\%)$ dos alimentos empregados nas dietas experimentais ${ }^{1}$.

\begin{tabular}{lcccccccc}
\hline \multicolumn{1}{c}{ Alimentos } & $\mathbf{M S}^{\mathbf{2}}$ & $\mathbf{M O}^{\mathbf{2}}$ & $\mathbf{P B}^{\mathbf{2}}$ & $\mathbf{F B}^{\mathbf{2}}$ & $\mathbf{E E}^{\mathbf{2}}$ & $\mathbf{E N N}^{\mathbf{2}}$ & $\mathbf{C a}^{\mathbf{2}}$ & $\mathbf{P}^{\mathbf{2}}$ \\
\hline Semente de girassol & 95,90 & 93,04 & 24,17 & 2,86 & 57,80 & 12,19 & 0,06 & 1,05 \\
Aveia & 89,00 & 86,96 & 13,95 & 1,68 & 9,12 & 72,96 & 0,09 & 0,43 \\
Gema de ovo & 97,22 & 91,25 & 38,69 & $\mathrm{ND}$ & 46,87 & 8,31 & 0,31 & 0,55 \\
Ovo integral & 95,65 & 91,25 & 51,84 & $\mathrm{ND}$ & 35,41 & 8,16 & 0,35 & 1,09 \\
Clara de ovo & 93,83 & 86,36 & 88,72 & $\mathrm{ND}$ & 0,66 & 2,66 & 0,06 & 0,21 \\
Germe de trigo & 88,65 & 83,87 & 29,46 & 2,42 & 9,18 & 53,56 & 0,06 & 0,73 \\
Farelo de trigo & 88,92 & 84,08 & 15,69 & 9,35 & 5,17 & 64,36 & 0,12 & 0,65 \\
Milho moído & 87,47 & 86,47 & 9,01 & 1,19 & 5,07 & 83,60 & 0,02 & 0,46 \\
Milho gelatinizado & 90,43 & 89,24 & 8,84 & 1,46 & 2,38 & 86,01 & 0,02 & 0,31 \\
Farelo de girassol & 91,00 & 87,13 & 27,24 & 27,35 & 3,44 & 37,72 & 0,24 & 0,58 \\
Levedura de cerveja & 90,13 & 83,55 & 44,82 & ND & 0,68 & 47,20 & 0,10 & 1,82 \\
Polpa cítrica & 88,81 & 84,29 & 11,66 & 9,43 & 3,36 & 70,46 & 1,08 & 0,28 \\
Mamão desidratado & 94,24 & 92,36 & 1,95 & ND & 1,03 & 95,04 & 0,06 & 0,27 \\
Banana desidratada & 91,73 & 87,48 & 5,45 & ND & 0,32 & 89,60 & 0,02 & 0,20 \\
Farelo de soja & 87,90 & 82,68 & 50,41 & 4,81 & 3,85 & 34,99 & 0,28 & 0,77 \\
Soja micronizada & 94,89 & 90,56 & 41,92 & 0,49 & 25,19 & 27,85 & 0,13 & 0,59 \\
\hline
\end{tabular}

1- Dados expressos na base da matéria seca.

2-.MS = matéria seca, $\mathrm{MO}=$ matéria orgânica, $\mathrm{PB}=$ proteína bruta, $\mathrm{FB}=$ fibra bruta, $\mathrm{EE}=$ extrato etéreo, $\mathrm{ENN}=$ extrativo não nitrogenado, $\mathrm{Ca}=$ cálcio, $\mathrm{P}=$ fósforo.

3- ND = Não detectado pelos limites da técnica. 
TABELA 2 - Composição química (\%) das dietas experimentais ${ }^{1}$.

\begin{tabular}{lccccc}
\hline \multicolumn{1}{c}{ Dietas experimentais } & $\mathbf{M S}^{\mathbf{2}}$ & $\mathbf{M O}^{\mathbf{2}}$ & $\mathbf{P B}^{\mathbf{2}}$ & $\mathbf{C z}^{\mathbf{2}}$ & $\mathbf{F B}^{\mathbf{2}}$ \\
\hline T1 - Ração referência & 91,73 & 86,98 & 18,01 & 5,18 & 2,26 \\
T3 - Ração + Aveia & 90,97 & 86,76 & 17,02 & 4,63 & 2,31 \\
T4 - Ração + Gema de ovo & 93,64 & 89,07 & 22,27 & 4,88 & 2,90 \\
T5 - Ração + Ovo integral & 91,36 & 86,85 & 27,12 & 4,94 & 2,04 \\
T6 - Ração + Clara de ovo & 93,37 & 88,00 & 38,39 & 5,76 & 2,22 \\
T7 - Ração + Germe de trigo & 92,89 & 88,13 & 21,77 & 5,13 & 2,33 \\
T8 - Ração + Farelo de trigo & 93,26 & 88,33 & 16,99 & 5,29 & 5,03 \\
T9 - Ração + Milho moído) & 90,71 & 86,90 & 15,36 & 4,19 & 2,61 \\
T10 - Ração + Milho gelatinizado & 91,36 & 87,65 & 15,67 & 4,06 & 1,94 \\
T11 - Ração + Farelo de girassol & 91,43 & 86,06 & 20,94 & 5,88 & 10,48 \\
T12 - Ração + Levedura de cerveja & 91,89 & 86,69 & 25,44 & 5,66 & 2,07 \\
T13 - Ração + Polpa cítrica & 92,41 & 87,71 & 15,95 & 5,09 & 3,96 \\
T14 - Ração + Mamão desidratado & 93,12 & 87,82 & 13,02 & 5,69 & 1,59 \\
T15 - Ração + Banana desidratada & 91,93 & 87,60 & 13,45 & 4,71 & 1,85 \\
T16 - Ração + Farelo de soja & 90,85 & 86,05 & 26,43 & 5,28 & 2,85 \\
T17 - Ração + Soja micronizada & 92,89 & 87,81 & 24,85 & 5,47 & 2,20 \\
\hline
\end{tabular}

Obs: Todas as rações passaram por um processo de extrusão.

1- Dados expressos com base na matéria seca.

2- $\mathrm{MS}=$ matéria seca, $\mathrm{MO}=$ matéria orgânica, $\mathrm{PB}=$ proteína bruta, $\mathrm{Cz}=$ cinzas, $\mathrm{FB}=$ fibra bruta.

TABELA 3 - Digestibilidade aparente e verdadeira (\%) da matéria seca (MS) e da matéria orgânica (MO) dos alimentos avaliados ${ }^{1}$.

\begin{tabular}{|c|c|c|c|c|}
\hline \multirow{2}{*}{ Alimentos } & \multicolumn{2}{|c|}{ Digestibilidade aparente } & \multicolumn{2}{|c|}{ Digestibilidade verdadeira } \\
\hline & MS & MO & MS & MO \\
\hline Semente de girassol & $84,43 \mathrm{a}$ & $86,00 \mathrm{a}$ & $88,96 \mathrm{~b}$ & $90,12 \mathrm{a}$ \\
\hline Aveia & $77,51 \mathrm{~b}$ & $79,00 \mathrm{~b}$ & $83,81 \mathrm{~b}$ & $83,77 \mathrm{~b}$ \\
\hline Gema de ovo & $86,53 \mathrm{a}$ & $87,45 \mathrm{a}$ & $95,72 \mathrm{a}$ & $95,13 \mathrm{a}$ \\
\hline Ovo Integral & $81,91 \mathrm{~b}$ & $82,92 \mathrm{~b}$ & $87,66 \mathrm{~b}$ & $87,32 \mathrm{~b}$ \\
\hline Clara de ovo & $47,19 \mathrm{c}$ & $48,48 \mathrm{~d}$ & $51,03 \mathrm{c}$ & $51,14 \mathrm{~d}$ \\
\hline Germe de trigo & $52,70 \mathrm{c}$ & $55,32 \mathrm{c}$ & $55,86 \mathrm{c}$ & $57,23 \mathrm{c}$ \\
\hline Farelo de trigo & $39,87 \mathrm{~d}$ & $41,40 \mathrm{e}$ & $41,51 \mathrm{~d}$ & $41,88 \mathrm{e}$ \\
\hline Milho moído & $78,79 \mathrm{~b}$ & $80,11 \mathrm{~b}$ & $85,28 \mathrm{~b}$ & $84,96 \mathrm{~b}$ \\
\hline Milho gelatinizado & $91,83 \mathrm{a}$ & $92,38 \mathrm{a}$ & $95,77 \mathrm{a}$ & $94,95 \mathrm{a}$ \\
\hline Farelo de girassol & $27,17 \mathrm{e}$ & $27,12 \mathrm{f}$ & $29,00 \mathrm{e}$ & $27,88 \mathrm{f}$ \\
\hline Levedura de cerveja & $52,49 \mathrm{c}$ & $54,41 \mathrm{c}$ & $55,26 \mathrm{c}$ & $56,00 \mathrm{c}$ \\
\hline Polpa cítrica & $21,23 \mathrm{e}$ & $22,60 \mathrm{f}$ & $23,46 \mathrm{e}$ & $23,62 \mathrm{f}$ \\
\hline Mamão desidratado & $82,91 \mathrm{~b}$ & $82,84 \mathrm{~b}$ & $87,47 \mathrm{~b}$ & $86,20 \mathrm{~b}$ \\
\hline Banana desidratada & $76,94 b$ & $79,36 \mathrm{~b}$ & $82,44 \mathrm{~b}$ & $83,45 \mathrm{~b}$ \\
\hline Farelo de soja & $39,81 \mathrm{~d}$ & $42,31 \mathrm{e}$ & $45,14 \mathrm{~d}$ & $46,26 \mathrm{e}$ \\
\hline Soja micronizada & $56,69 \mathrm{c}$ & $58,71 \mathrm{c}$ & $61,67 \mathrm{c}$ & $62,43 \mathrm{c}$ \\
\hline $\mathrm{CV}(\%)$ & 9,01 & 8,01 & 7,90 & 7,28 \\
\hline
\end{tabular}

1- Valores em uma mesma coluna, seguidos de letras distintas, diferem pelo teste de Scott-Knott $(\mathrm{P}<0,05)$. 
O milho gelatinizado apresentou digestibilidade aparente da MS 16,54\% maior que a digestibilidade aparente da MS do milho moído $(\mathrm{P}<0,05)$. Do mesmo modo, para a digestibilidade aparente da $\mathrm{MO}$ e digestibilidade verdadeira da MS e MO, o milho gelatinizado apresentou, respectivamente, percentual maior de 15,33, 12,39 e 11,76\% que o milho moído. Este aumento da digestibilidade pode, provavelmente, ser atribuído à gelatinização do amido que favorece o ataque enzimático.

A digestibilidade aparente e verdadeira, tanto da MS quanto da $\mathrm{MO}$, da clara do ovo foi menor $(\mathrm{P}<0,05)$ que a da gema ou do ovo integral. Sendo alimento de origem animal e, considerado de alto valor biológico, a clara de ovo deveria ter apresentado alta digestibilidade da MS e MO. Porém, esta baixa digestibilidade pode estar relacionada ao alto teor protéico $(38,39 \%$ de $\mathrm{PB})$ da ração teste (T6), pois continha quase $30 \%$ de clara de ovo com $88,72 \%$ de proteína bruta. A clara de ovo apresentou digestibilidades aparente e verdadeira da MS e MO semelhantes $(\mathrm{P}>0,05)$ àquelas do germe de trigo, da levedura e da soja micronizada, produtos de origem vegetal que, teoricamente, deveriam apresentar digestibilidade menor que a dos produtos de origem animal.

O farelo de soja e a soja micronizada também apresentaram digestibilidades aparente e verdadeira da MS e MO distintas entre si $(\mathrm{P}<0,05)$, porém a soja micronizada, quando comparada ao farelo de soja, apresentou teor mais alto de extrato etéreo e mais baixo de fibra.

Para os farelos de trigo e de soja foram encontrados valores de digestibilidade aparente e verdadeira da MS e MO semelhantes $(\mathrm{P}>0,05)$, embora estes alimentos apresentem composição bromatológica distintas, pois o trigo possui quase um terço da proteína da soja e quase o dobro de fibra.

A polpa cítrica e o farelo de girassol obtiveram as mais baixas digestibilidades aparente e verdadeira da MS e MO, com valores estatisticamente semelhantes $(\mathrm{P}>0,05)$ entre si e diferentes $(\mathrm{P}<0,05)$ dos demais alimentos. Ambos os alimentos apresentaram alto teor de fibra bruta, porém a FB do farelo de girassol $(27,35 \%)$ é maior que a da polpa cítrica $(9,43 \%)$. Embora não seja quantificada como fibra bruta, a polpa cítrica possui grande proporção de pectina, substância não digerida por nenhuma enzima endógena presente no trato digestivo das aves, em razão das ligações b1-4 em sua cadeia. Dessa forma, possivelmente, grande parte do extrativo não nitrogenado seja pectina, o que diminui consideravelmente a digestibilidade da MS e MO deste alimento para não ruminantes.

Na Tabela 4, encontram-se os valores relativos à retenção de nitrogênio aparente (RAN) e verdadeira (RVN) e os coeficientes de metabolização aparente $\left(\mathrm{CMA}_{\mathrm{PB}}\right)$ e verdadeiro $\left(\mathrm{CMV}_{\mathrm{PB}}\right)$ da proteína bruta dos alimentos avaliados.

TABELA 4 - Retenção de nitrogênio aparente (RAN) e verdadeira (RVN), em gramas, e coeficientes de metabolização aparente $\left(\mathrm{CMA}_{\mathrm{PB}}\right)$ e verdadeiro $\left(\mathrm{CMV}_{\mathrm{PB}}\right)$ da proteína bruta $(\%)$ dos alimentos avaliados ${ }^{1}$.

\begin{tabular}{lcccc}
\hline \multicolumn{1}{c}{ Dietas experimentais } & RAN & RVN & CMA $_{\mathbf{P B}}$ & $\mathbf{C M V}_{\mathbf{P B}}$ \\
\hline Semente de girassol & $0,36 \mathrm{a}$ & $0,51 \mathrm{a}$ & $52,03 \mathrm{a}$ & $77,92 \mathrm{a}$ \\
Aveia & $0,10 \mathrm{~b}$ & $0,26 \mathrm{~b}$ & $16,84 \mathrm{~b}$ & $49,10 \mathrm{a}$ \\
Gema de ovo & $0,55 \mathrm{a}$ & $0,72 \mathrm{a}$ & $65,96 \mathrm{a}$ & $86,63 \mathrm{a}$ \\
Ovo integral & $0,52 \mathrm{a}$ & $0,68 \mathrm{a}$ & $63,33 \mathrm{a}$ & $82,98 \mathrm{a}$ \\
Clara de ovo & $0,91 \mathrm{a}$ & $1,06 \mathrm{a}$ & $51,48 \mathrm{a}$ & $63,21 \mathrm{a}$ \\
Germe de trigo & $0,41 \mathrm{a}$ & $0,55 \mathrm{a}$ & $44,87 \mathrm{a}$ & $64,23 \mathrm{a}$ \\
Farelo de trigo & $0,21 \mathrm{~b}$ & $0,37 \mathrm{~b}$ & $17,29 \mathrm{~b}$ & $38,43 \mathrm{~b}$ \\
Milho moído & $-0,003 \mathrm{~b}$ & $0,16 \mathrm{~b}$ & $-29,22 \mathrm{~b}$ & $6,92 \mathrm{~b}$ \\
Milho gelatinizado & $0,19 \mathrm{~b}$ & $0,34 \mathrm{~b}$ & $29,81 \mathrm{a}$ & $58,76 \mathrm{a}$ \\
Farelo de girassol & $0,58 \mathrm{a}$ & $0,74 \mathrm{a}$ & $60,12 \mathrm{a}$ & $77,61 \mathrm{a}$ \\
Levedura de cerveja & $0,67 \mathrm{a}$ & $0,82 \mathrm{a}$ & $64,14 \mathrm{a}$ & $80,09 \mathrm{a}$ \\
Polpa cítrica & $-0,02 \mathrm{~b}$ & $0,13 \mathrm{~b}$ & $-5,71 \mathrm{~b}$ & $18,32 \mathrm{~b}$ \\
Mamão desidratado & $0,13 \mathrm{~b}$ & $0,28 \mathrm{~b}$ & $5,00 \mathrm{~b}$ & $41,99 \mathrm{~b}$ \\
Banana desidratada & $-0,09 \mathrm{~b}$ & $0,06 \mathrm{~b}$ & $-23,80 \mathrm{~b}$ & $14,77 \mathrm{~b}$ \\
Farelo de soja & $0,38 \mathrm{a}$ & $0,53 \mathrm{a}$ & $38,327 \mathrm{a}$ & $57,56 \mathrm{a}$ \\
Soja micronizada & $0,61 \mathrm{a}$ & $0,76 \mathrm{a}$ & $52,76 \mathrm{a}$ & $72,83 \mathrm{a}$ \\
\hline CV (\%) & 130,22 & 59,26 & 103,87 & 69,89 \\
\hline
\end{tabular}

1- Valores em uma mesma coluna, seguidos de letras distintas, diferem pelo teste de $\mathrm{Scott}-\mathrm{Knott}(\mathrm{P}<0,05)$. 
A retenção de nitrogênio verdadeiro foi positiva para todas as aves, sugerindo que ainda estariam depositando tecidos, entretanto, a retenção de $\mathrm{N}$ aparente foi negativa para as aves que receberam milho moído, polpa cítrica e banana. Como a retenção de $\mathrm{N}$ pode ser influenciada por inúmeros fatores, entre eles o equilíbrio de aminoácidos do alimento, fica difícil determinar porque somente estes três alimentos apresentaram balanço negativo de $\mathrm{N}$.

Como os coeficientes de variação $(\mathrm{CV})$ da retenção de nitrogênio aparente e verdadeiro (130,22 e 59,26\%, respectivamente), coeficientes de metabolização aparente $\left(\mathrm{CMA}_{\mathrm{PB}}\right)$ e verdadeiro da proteína bruta $\left(\mathrm{CMV}_{\mathrm{PB}}\right)(103,87 \mathrm{e}$ $69,89 \%$, mesma ordem) foram muito altos, alimentos com valores numericamente muito diferentes não apresentaram diferenças estatísticas entre si. Este foi o caso do grupo composto pela semente de girassol, gema de ovo, ovo integral, clara de ovo, germe de trigo, farelo de trigo, farelo de girassol e levedura, que foram estatisticamente iguais entre si $(\mathrm{P}>0,05)$, mas que diferiram $(\mathrm{P}<0,05)$ do grupo formado pela aveia, farelo de trigo, milho moído e milho gelatinizado.

\section{CONCLUSÕES}

Os resultados obtidos neste estudo permitiram as seguintes conclusões:

O milho gelatinizado, a gema de ovo, a semente de girassol, a aveia, o ovo integral, o milho moído, o mamão e a banana, possuem alta digestibilidade da MS e MO para papagaios-verdadeiros (Amazona aestiva), podendo ser considerados como boas opções de escolha para a composição de uma dieta completa.

A polpa cítrica e o farelo de girassol apresentaram baixos valores de digestibilidade aparente e verdadeira da MS e MO.

A retenção de nitrogênio verdadeiro foi positiva para todas as aves.

\section{REFERÊNCIAS BIBLIOGRÁFICAS}

CARCIOFI, A. C. Avaliação de dieta à base de sementes e frutas para papagaios (Amazona sp): determinações da seletividade dos alimentos, consumo, composição nutricional, digestibilidade e energia metabolizável. 1996. 104 f. Dissertação (Mestrado) - Faculdade de Medicina Veterinária e Zootecnia, Universidade de São Paulo, São Paulo, 1996.

CUNNIFF, P. (Ed.). Official methods of analysis of AOAC International. 16. ed. Arlington: AOAC International, 1995. v. 1.

EARLE, K. E.; CLARKE, N. R. The nutrition of the Budgerigar (Melopsittacus undulatus). Journal of Nutrition, Philadelphia, v. 121, p. S186-S192, 1991. Supplement 11.

MATTERSON, L. D.; POTTER, L. M.; STUTZ, M. W.; SINGSEN, E. P. The metabolizable energy of feed ingredients for chickens. Storrs: The University of Connecticut, 1965. 11 p. (Research report, 7).

McNAB, J. M.; BLAIR, J. C. Modified assay for true and apparent metabolizable energy based on tube feeding. British Poultry Science, London, v. 29, n. 4, p. 697-707, 1988.

MEJÍA, A. M. G; FERREIRA, W. M. Métodos de avaliação da disponibilidade da proteína e dos aminoácidos nos alimentos para não ruminantes. In: SIMPÓSIO INTERNACIONAL DEANIMAIS SILVESTRES, 1., 1996, Rio de Janeiro. Anais... Rio de Janeiro: UFRRJ, 1996. 1996. Disquete.

SAS INSTITUTE. SAS user's guide: statistics. Cary, 1995. $956 \mathrm{p}$.

ULLREY, D. E.; ALLEN, M. E.; BAER, D. J. Formulated diets versus seed mixtures for psittacines. Journal of Nutrition, Philadelphia, v. 121, n. 11S, p. 193-205, 1991. 